\title{
Ultrastructure and Phototaxis of the Zoospores of Phlyctochytrium sp., an Estuarine Chytrid
}

\author{
By F. Y. KAZAMA \\ Virginia Institute of Marine Science, Gloucester Point, \\ Virginia, 23062, U.S.A.
}

(Accepted for publication 6 March 1972)

\begin{abstract}
SUMMARY
Zoospores of an estuarine fungus isolated from Bryopsis plumosa and tentatively identified as a species of Phlyctochytrium were positively phototactic. Electron microscopy revealed a complex of organelles consisting of a relatively electron opaque, membrane-bounded sac, a lipid droplet and a highly ordered array of membranous tubular units which may have been involved in photoreception. The ribosomes of the zoospores were aggregated into a 'nuclear cap' and separated from the rest of the cytoplasm by mitochondria, the nucleus, membranous sheets and membrane-bounded vesicles. There was a vestigial kinetosome nearly parallel to the functional kinetosome. A Golgi-like body was associated with the nucleus.
\end{abstract}

\section{INTRODUCTION}

Ultrastructural studies of posteriorly uniflagellated zoospores of freshwater fungi (Fuller, 1966; Fuller \& Olson, 1971; Travland \& Whisler, 197I) indicate that they vary widely in morphology. The posteriorly uniflagellated zoospores of an estuarine, eucarpic, epibiotic-endobiotic, non-operculate organism tentatively identified as Phlyctochytrium sp. (Kazama, 1972) proved to be positively phototactic and differed in ultrastructure from other uniflagellated fungal zoospores.

\section{METHODS}

A single spore isolate of a fungus, designated isolate 7I-I-E, tentatively identified as Phlyctochytrium sp. was isolated from Bryopsis plumosa (Hudson) C. Agardh and maintained as described elsewhere (Kazama, 1972). Petri dishes containing a medium of $7.5 \mathrm{~g}$ soluble starch (Nutritional Biochemical Company), 2.0 g yeast extract (Difco), I5.0 g Bacto-agar (Difco), and I litre of York River (Virginia, U.S.A.) water of approx. 20\%o salinity were inoculated by spreading a few drops of a zoospore suspension on the agar surface. After $72 \mathrm{~h}$ of growth in the dark at $20 \pm \mathrm{I}{ }^{\circ} \mathrm{C}$, the plates were immediately flooded with Io $\mathrm{ml}$ of sterile estuarine water (approx. $20 \%$ salinity) or placed at $4{ }^{\circ} \mathrm{C}$ until zoospores were needed. Zoospores were utilized 30 to $90 \mathrm{~min}$ after flooding.

Phototactic studies. Light from a microscope illuminator (American Optical Company, Model I I I44) with a General Electric Company lamp (Model I493) operated at 7.5 V was passed through $35 \mathrm{~cm}$ of estuarine water in a glass aquarium. By means of the base of a binocular microscope (AO Series 585), the light was then reflected through the glass stage into a $6.0 \mathrm{~cm}$ glass or plastic Petri dish containing the zoospore suspension. All of the exposed surfaces of the Petri dishes, except for the bottoms, were enameled black and the experiments carried out in a darkroom. 
Electron microscopy. Zoospores were fixed for Io to $30 \mathrm{~min}$ at room temperature in $\mathrm{I} \cdot 0 \%(\mathrm{~V} / \mathrm{v})$ glutaraldehyde prepared by the dilution of commercial $50 \%$ glutaraldehyde solution with $0 . \mathrm{I}$ M-Millonig's phosphate buffer, $\mathrm{pH}]_{7} \cdot 4$ (Kay, I965), containing $0.15 \mathrm{M}-\mathrm{NaCl}$, or with equal parts $0.2 \mathrm{M}$-cacodylate buffer, $\mathrm{pH} 7 \cdot 2$, and estuarine water approx. $20 \%$ salinity. The zoospores were then washed with the phosphate buffer or the cacodylate buffer-estuarine water solution. This was followed by fixation at room temperature with $\mathrm{I} \cdot 0 \%(\mathrm{w} / \mathrm{v}) \mathrm{OsO}_{4}$ dissolved in $0 . \mathrm{I} \mathrm{M}$-Millonig's phosphate $(\mathrm{pH} 7 \cdot 4)$ or $0 . \mathrm{I}$ M-cacodylate $(\mathrm{pH} 7 \cdot 2$ ) buffer for varying lengths of time ranging from $20 \mathrm{~min}$ to $\mathrm{I} 2 \mathrm{~h}$. For permanganate fixation, iced (approximately 3 to $5{ }^{\circ} \mathrm{C}$ ) $\mathrm{I} \cdot 0 \%(\mathrm{w} / \mathrm{v})$ aqueous $\mathrm{KMnO}_{4}$ or a $\mathrm{I} \cdot 0 \%(\mathrm{w} / \mathrm{v})$ $\mathrm{KMnO}_{4}$ solution prepared with estuarine and distilled water (I:I) were utilized. After fixation, the zoospores were pelleted, enrobed in $2.0 \%$ (w/v) agar, cut into pieces and dehydrated in a graded ethyl alcohol series followed by several changes of propylene oxide. The zoospores were embedded in Durcupan ACM (Fluka), sectioned and stained with uranyl acetate and lead citrate.

For negatively stained preparations, the zoospores were first pelleted with a clinical centrifuge and then lysed either by draining off the supernatant followed by the rapid addition of $\mathrm{I} \mathrm{ml}$ of distilled water or by gentle sonication for $\mathrm{I} 5 \mathrm{~S}$ in a small volume of supernatant. The lysed zoospores were placed on formvar-coated grids, allowed to settle for a few minutes, and the liquid was then drawn off with filter paper. While the grids were still moist, droplets of $0.8 \%(\mathrm{w} / \mathrm{v})$ potassium phosphotungstate $(\mathrm{pH} 7 \cdot 0)$ were applied to the grids and then promptly withdrawn with filter paper. The grids were allowed to air dry for a few minutes and were immediately examined.

For shadowed preparations, a droplet of a zoospore suspension was placed on formvarcoated grids which were then exposed to the fumes from a $2 \cdot 0 \%(\mathrm{w} / \mathrm{v}) \mathrm{OsO}_{4}$ solution for $2 \mathrm{~min}$. The zoospores were allowed to settle for $\mathrm{Io} \mathrm{min}$. The grids were then rapidly rinsed with distilled water and after drying were shadowed at an angle of approximately $20^{\circ} \mathrm{C}$ with platinum-palladium $(80: 20)$ in a Hitachi HUS-3B vacuum evaporator. All electron microscopic observations were made with a Hitachi HU-I IB electron microscope.

\section{RESULTS}

Zoospores were exposed for $60 \mathrm{~s}$ to the fumes from $2 \cdot 0 \%$ aqueous $\mathrm{OsO}_{4}$ and viewed with the light microscope (Fig. I). The only readily identifiable structures were the spore body, the single lateral refractile lipid droplet (highly osmiophilic and staining with Sudan IV) and the single, posteriorly directed flagellum. Shadowed zoospores (Fig. 2) showed a typical whiplash flagellum and possibly the lipid droplet located laterally within the zoospore body.

Longitudinal sections of the zoospores showed a single nucleus, whose double membranes seemed to be punctuated by nuclear pores only in the areas not bounded by the ribosomal

Fig. I. Photomicrograph of the posteriorly uniflagellate zoospores of Phlyctochytrium sp. showing lipid droplet (L).

Fig. 2. Shadowed preparation of zoospore showing typical whiplash-type posterior flagellum and possibly the lipid droplet $(\mathrm{L})$.

Fig. 3. Longitudinal section of the zoospore showing nucleus $(\mathrm{N})$, lipid droplet (L), tubular elements (TE), electron-opaque sac (ES), dictyosome-like organelle (D), nuclear pore (NP), mitochondria (M), electron-opaque vesicles (OV), electron-transparent vesicles (TV), microtubules (MT), membranous extension of outer nuclear membrane (EN), ribosomal aggregate (RA).

Fig. 4. Tangential section of zoospore showing double membrane (RM) delimiting parts of the ribosomal aggregate from the cytoplasm. (See legend for Fig. 3.) 

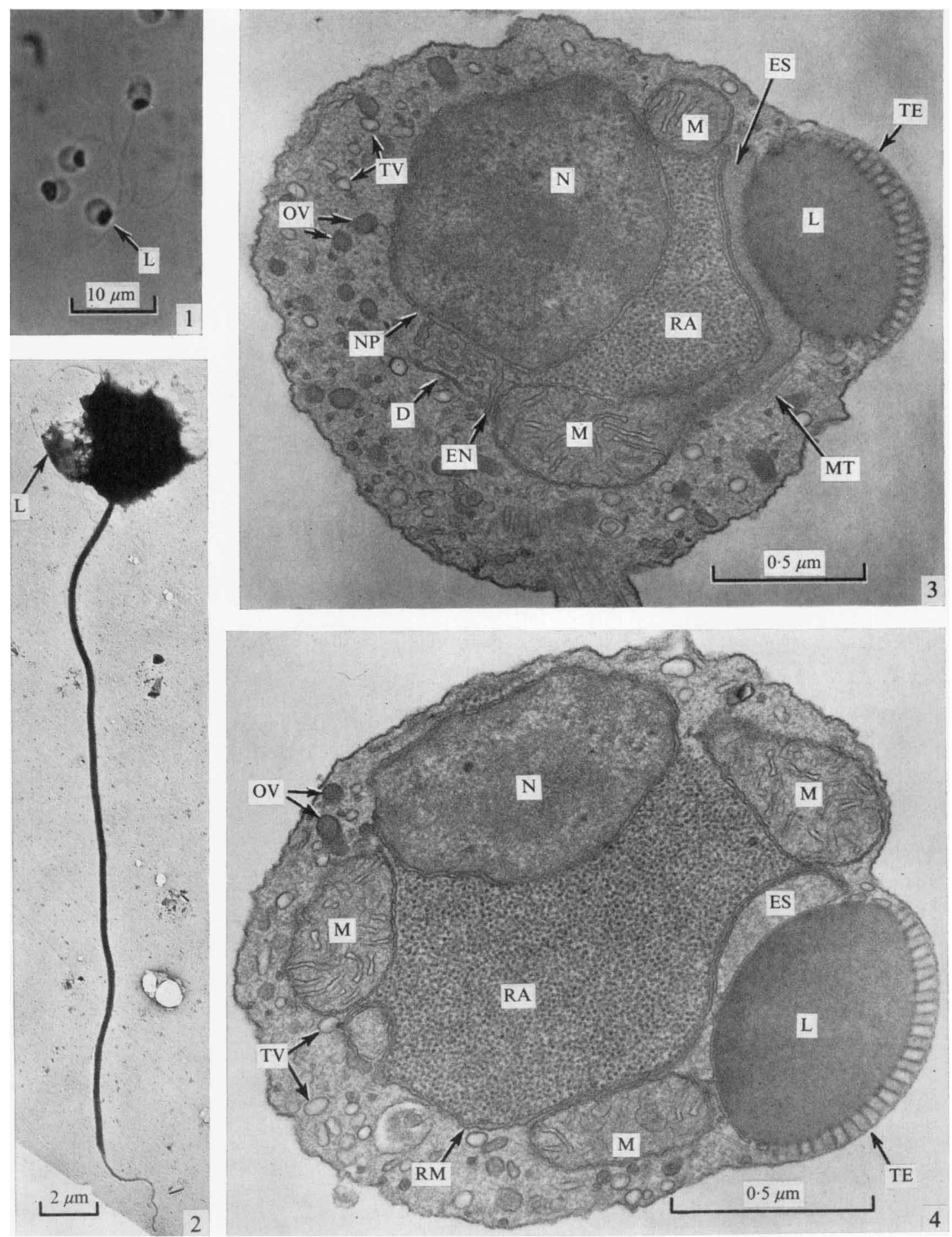

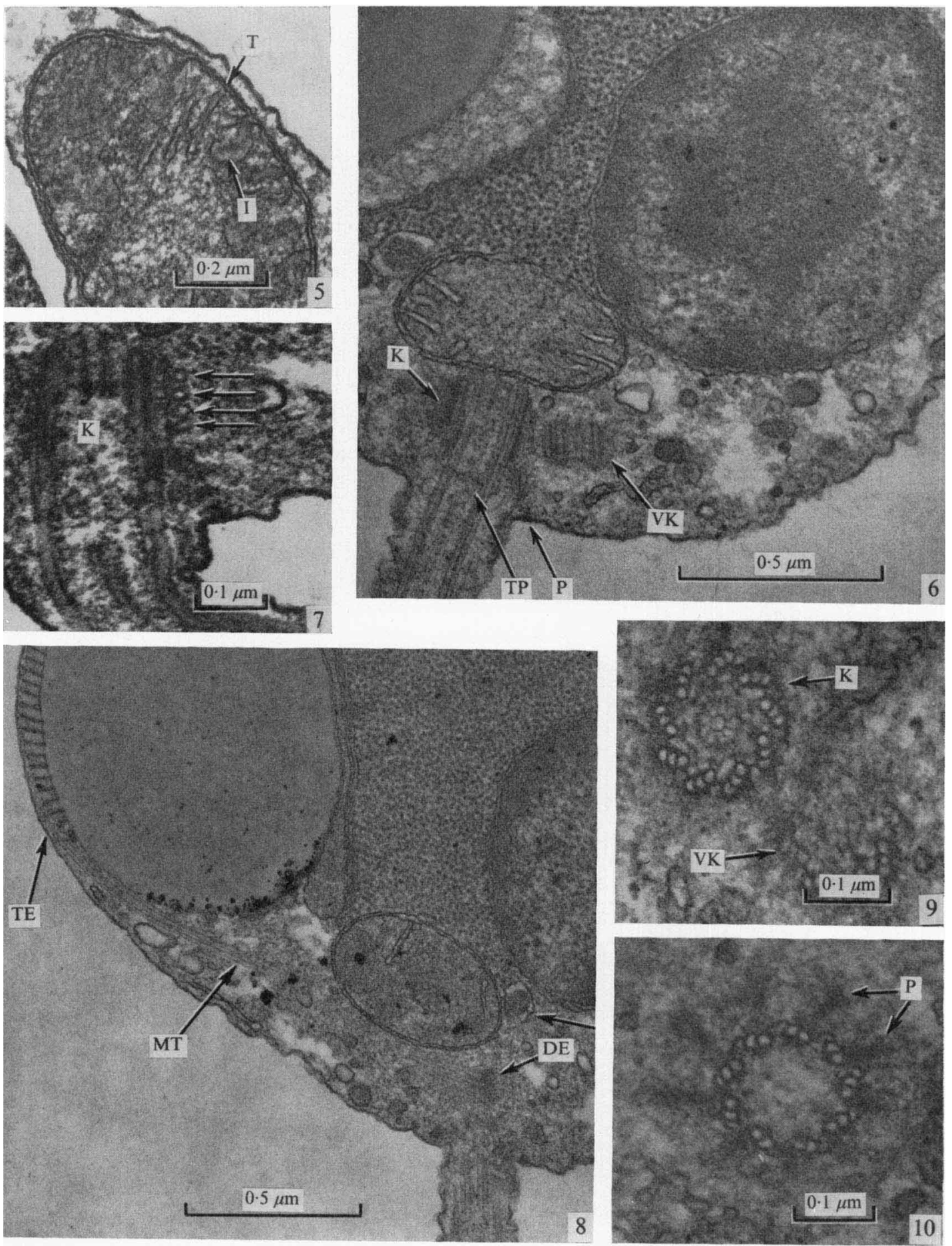
aggregate (Fig. 3,6). In some sections the outer membrane of the nucleus formed ER-like sheets extending into the cytoplasm (Fig. 3). Associated with these membranes was a series of flattened cisternae and vesicles which resembled a Golgi complex. This organelle was usually close to the ribosomal aggregate. There were many electron-opaque and electrontransparent, single membrane-bounded vesicles present in the cytoplasm.

'Nuclear cap' and mitochondria. The abundant ribosomes were aggregated (Fig. 3,4) and were partially delimited from the remainder of the cytoplasm by sheets of membranes, mitochondria, portions of the nucleus and by single membrane bounded vesicles (Fig. 8). Although the enclosure of the ribosomes from the remainder of the cytoplasm was nearly complete, there appeared to be occasional, limited areas where the ribosomal aggregate was not separated from the rest of the cytoplasm. On rare occasions, membranous elements were found within the ribosomal aggregate (not illustrated). There appeared to be at least two, generally more, mitochondria in each zoospore (Fig. 3, 4). The mitochondrial cisternae were plate-like and appeared as tubes or inflated sacs (Fig. 3, 4, 5). Sections that passed through the longitudinal axis of the functional kinetosome frequently showed a mitochondrion close to the proximal end of the kinetosome (Fig. 6).

Kinetosomes. There was a kinetosome as well as other structures at the base of the single, posteriorly directed, whiplash flagellum. The kinetosome, measured from the proximal end to the terminal plate, was about $265 \mathrm{~nm}$ long and $\mathrm{I} 70 \mathrm{~nm}$ wide. Lying beside the kinetosome and skewed slightly from a line passing through the central axis of the kinetosome was a vestigial kinetosome (Koch, I956; Olson \& Fuller, 1968) (Fig. 6). A series of microtubules, probably four (Fig. 7), originating from an electron-dense area (Fig. 8) in the vicinity of the kinetosome was found traversing the cytoplasm to the region of the presumed photoreceptor (see below). The hub of the kinetosome (Fig. 9) consisted of two concentric membranous elements with a series of nine elements radiating from the inner to the outer ring. Some cross-sections (Fig. I0) showed a system of props (Olson \& Fuller, 1968). This organelle was presumed to be the kinetosome since evidence of props associated with the vestigial kinetosome has not been observed.

Lipid body and associated structures. Perhaps the most interesting feature of the zoospores is a group of structures which may form a morphological and functional unit. This complex consisted of a highly organized membranous system just beneath the plasmalemma, a lipid body, and a membrane bounded, cup-like structure (Fig. 3). Serial sectioning through this presumed 'eyespot' (Fig. 22-26) showed that the amorphous, usually slightly electron dense, cup-like structure sheathed approximately one-third to one-half of the lipid surface facing the interior of the zoospore. The cup-like structure was bounded by a single unit membrane (Fig. 8, 25). The lipid droplet, which ranged from spherical to highly oblate,

Fig. 5. Mitochondrion displaying tubular (T) and inflated (I) profiles of the plate-like cisternae.

Fig. 6. Longitudinal section of zoospore showing functional kinetosome $(\mathbf{K})$, vestigial kinetosome (VK), 'props' (P) associated with kinetosome (K) and the terminal plate of the kinetosome (TP).

Fig. 7. Cross-section of microtubules (arrows) associated with the functional kinetosome (K).

Fig. 8. Microtubules (MT) originating from an electron-dense area (DE) and passing in the vicinity of the tubular elements (TE). Arrow indicates a membrane-bounded vesicle which aids in delimiting the ribosomal aggregate from the cytoplasm.

Fig. 9. Cross-section of kinetosome (K) showing the typical pinwheel arrangement of the peripheral microtubules and the central hub. Also present is an oblique cross-section of the vestigial kinetosome (VK).

Fig. 1o. Cross-section of the kinetosome, possibly in the region of transition between doublet and triplet peripheral fibres, showing the nine 'props' $(\mathrm{P})$. 

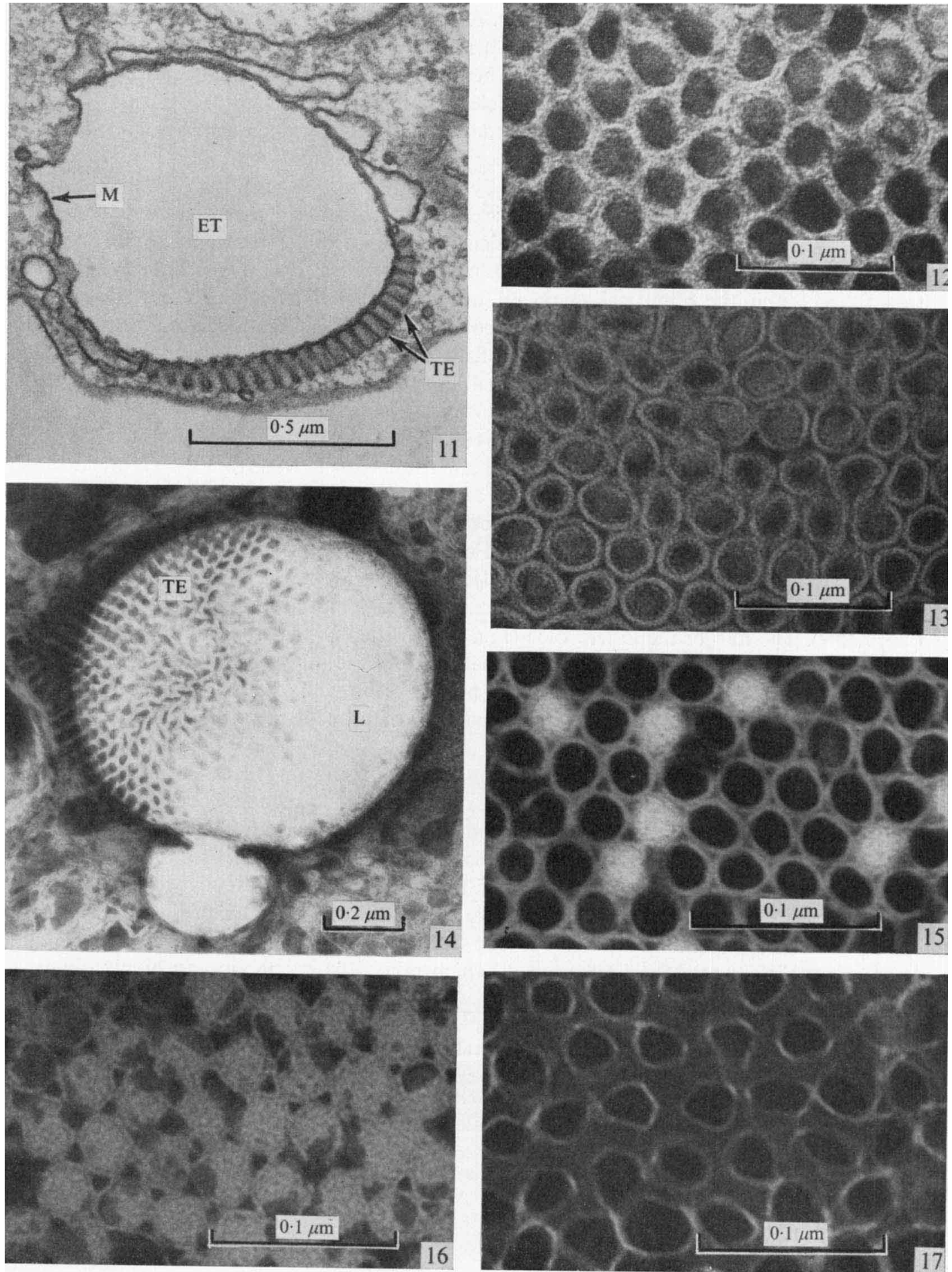
appeared to be surrounded by a unit membrane in $\mathrm{KMnO}_{4}$ fixed zoospores (Fig. I I), but the membrane was not apparent in glutaraldehyde-osmium fixed cells.

Sheathing approximately one-third to one-half of the lipid droplet surface which faced towards the exterior of the cell was a highly organized system of membranous tubes (Fig. 3, I I, I4). Negatively stained preparations of distilled water-lysed zoospores showed two different surface configurations of the tubular elements (Fig. I2, I3). It is not clear whether one or the other of these configurations was a preparation artifact. One configuration (Fig. I2) of the tubes was a closely packed array of hexagonal units. The centre to centre distance of the hexagonal units ranged from 38.0 to $40 \cdot 0 \mathrm{~nm}$. Each common 'wall' between two adjacent hexagonal lumina (Fig. I2) measured approximately $12.0 \mathrm{~nm}$. Some of the lumina of the tubes appeared to be filled with a substance which excluded negative stain but others seemed to be hollow, permitting penetration of the stain. After distilled water lysis of the zoospores, the membranous complex frequently remained attached to the lipid droplet, indicating that they were a structural unit (Fig. I4).

The second surface view configuration of the tubular elements, which was present in some negatively stained preparations (Fig. 13), showed the tubes as separated circular elements rather than closely appressed hexagons. The centre to centre distance of the circular units, in areas where they were closely packed, ranged from 38.0 to $40^{\circ} 0 \mathrm{~nm}$ while the 'rim' of the circular units ranged from 4.0 to $5.0 \mathrm{~nm}$. As with the hexagonal configuration, the lumina appeared to be hollow in some cases but filled in others. The filled lumen displayed a series of concentric layers (Fig. I3). Within the outer ' rim', there was a rather electron-opaque ring followed by an electron-transparent ring and finally a centre portion which varied in electron opacity.

When the zoospores were ruptured by gentle sonication rather than lysed with distilled water, most of the tubular elements remained in the hexagonal configuration (Fig. 15). The region separating two adjacent 'rims' was now much more pronounced than in the distilled water-lysed preparations. Some preparations showed that many of the lumina may have been filled or covered by a substance not penetrated by the negative stain (Fig. I6). In a few preparations the membranous structure appeared as widely separated electron-transparent rings (Fig. I7).

Sections which passed through the membranous system, tangential to the surface of a glutaraldehyde-osmium or permanganate fixed cell, showed a cross-sectional view of the

Fig. II. Portion of a zoospore after permanganate fixation showing the presumed photoreceptor complex. Tubular elements (TE), an electron-transparent region (ET) representing lipid-extracted site and a presumed membrane (M) surrounding the ET are present.

Fig. I 2. Negatively stained preparation of portions of the tubular elements which are associated with the lipid droplet. Note that some hexagons are relatively electron opaque and others electron transparent.

Fig. I3. Portions of the tubular elements which show the circular configuration of the tubes that is sometimes present after distilled water lysis of the zoospores (compare to Fig. 12). Most of the lumina appear to exclude the negative stain.

Fig. I4. Negatively stained preparation of lipid droplet (L) with associated tubular elements (TE). Fig. I5. Negatively stained preparation of tubular elements after disruption of zoospores by gentle sonication. The tubes are arranged in a regular hexagonal pattern.

Fig. 16. Negatively stained preparation of the tubular elements after gentle sonication showing the exclusion of the negative stain from most of the lumina of the tubes.

Fig. 17. Negatively stained preparation of the tubular elements after gentle sonication showing them as widely spaced tubes. 

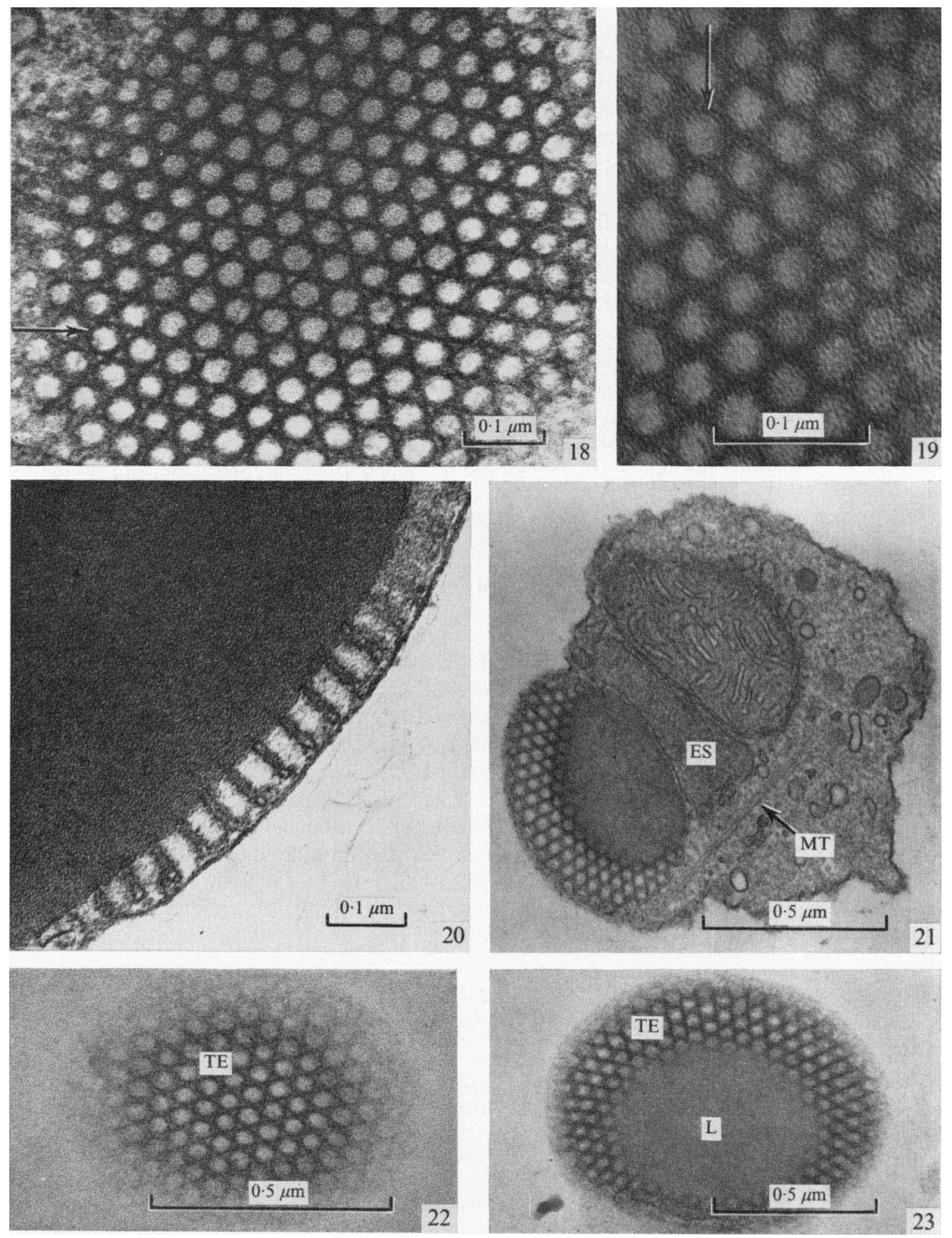
membranous tubes which appeared as unit-membrane rings (arrows) in highly ordered arrays (Fig. 18, 19). The centre to centre distance between units was approximately $38 \cdot 0$ to $40 \cdot 0 \mathrm{~nm}$. The membranes forming the rings measured approximately 5.0 to $6.0 \mathrm{~nm}$ in width while the width of two adjacent unit membranes at the narrowest juncture of two rings was approximately $\mathrm{I} 2.0$ to $14.0 \mathrm{~nm}$. After fixation of the zoospores in glutaraldehyde-osmium, membranes of the tubes sectioned through the long axis (Fig. 20) were difficult to resolve, but loops of unit membranes were seen with one end of the loop embedded in the lipid droplet. Tangential views of the tubes (Fig. 2I) at times showed the microtubules which passed from the region of the kinetosome to the vicinity of the complex.

Since it is conceivable that the lipid droplet and associated structures were involved in photoreception (see below) and that the exact morphological relationship between the three components should be known before future physiological studies can be interpreted, portions of a zoospore serial section sequence are presented here (Fig. 22-26). In this sequence, the sectioning proceeded slightly to one side of the apex of the tubular system. The micrographs show that the components were intimately associated with each other. The membrane-bounded body was cup-shaped with rather bulging sides and flattened bottom (Fig. 25, 26). The tubular system and lipid droplet protruded above the general contour of the zoospore surface.

Phototaxis. It was noticed that after flooding cultures on agar with estuarine water, the discharged zoospores accumulated on the side of the Petri dish nearest a window. Phototaxis was confirmed by illuminating Petri dishes containing zoospores from below as described in the Methods. A blackened piece of thick paper, with an ' $\mathrm{X}$ ' pattern ( $\mathrm{I} \cdot 5 \mathrm{~cm}$ to the crosspieces) cut out, was placed on the binocular microscope stage between the light source and the zoospore suspension. The zoospore suspension was illuminated for 2 min and then a direct contact print of the zoospore distribution was made by replacing the ' $X$ ' patterned paper with photographic paper and using a photographic enlarger as a light source. Zoospores had accumulated in the illuminated area (Fig. 27).

\section{DISCUSSION}

Phototaxis or a movement response to asymmetrical illumination appears to be relatively rare in fungi (Page, 1965; Carlile, 1970). Sparrow (1960, see pp. 67-68) citing from the earlier literature, indicates that at least three genera of chytrids may show phototactic responses. Perkins \& Amon (1969) observed positive phototaxis in the zoospores of Labyrinthula sp. (L. algeriensis). The photoreceptor appeared to be a stigma which resembled that of the euglenoids (Perkins \& Amon, 1969).

Fig. I 8. Near cross-section of tubular elements close to the cell surface of a glutaraldehyde-osmium fixed cell showing the tubes to be unit-membrane bounded (arrow).

Fig. 19. Near cross-section of tubular elements close to the surface of a $\mathrm{KMnO}_{4}$ fixed zoospore showing the unit-membrane nature of the tubes (arrow).

Fig. 20. Longitudinal section of the tubular elements. The lateral walls of two adjacent tubes appear to be a membrane loop.

Fig. 2I. Tangential section of tubular elements probably displaying a lateral view of rows of tubes. Also present are portions of the electron-opaque cup-like structure (ES) as well as a microtubule (MT) which possibly originates from the functional kinetosome.

Fig. 22-26. Selected micrographs of a serial section series of the presumed light receptor complex. Micrographs of the complex are arranged so that they appear as if one is observing sections progressively towards the interior of the cell. Represented are tubular elements (TE), lipid droplet (L), cell surface (CS), electron-opaque sac (ES), mitochondria (M), ribosomal aggregate (RA). 



Fig. 24-26. See legend for Fig. 22-26 on previous page.

Fig. 27. Reproduction of a direct contact print of the zoospore distribution after 2 min light stimulation. 
In isolate $7 \mathrm{I}-\mathrm{I}-\mathrm{E}$, it seems plausible that the tubular, membranous elements, lipid droplet and the membrane-bounded cup complex was a photoreceptive organelle. The structure of the complex may be identical to the 'fibrous body' and its associated organelles of Nowakowskiella profusa Karling described by Chambers, Markus \& Willoughby (1967) and perhaps similar to that of Chytridium (Koch, 1956; Schnepf, Deichgräber, Hegewald \& Soeder, I97I) but appears to be distinct from the rumposome in Monoblepharella sp. (Fuller \& Reichle, I968) and Harpochytrium hedinii Wille (Travland \& Whisler, I97I).

The rumposome found in Monoblepharella sp. (Fuller \& Reichle, 1968) was described as a system of three levels of tubules which were interconnected with other tubules to form a network. In isolate $7 \mathrm{I}-\mathrm{I}-\mathrm{E}$, the tubular elements are interpreted to be composed of unitmembrane bounded, closely packed tubules which are not connected laterally by other tubules. The 'holes' in cross-sectional views of the organelle represent the lumina of the tubes in 7I-I-E, but in Monoblepharella they seem to be intertubular spaces (Fuller \& Reichle, I968; see their Fig. 8, 10). The rumposome, therefore, appears to differ from the tubular complex although Fuller \& Reichle (1968) suggested that the rumposome may be similar to the fibrous body of Nowakowskiella profusa (Chambers, Markus \& Willoughby, 1967).

Except for having rectangular profiles in cross-section, the gridded plate found in Harpochytrium hedinii (Travland \& Whisler, 197I) appears to be morphologically similar to the tubular elements of isolate $7 \mathrm{I}-\mathrm{I}-\mathrm{E}$. The arrangement of the tubular elements (gridded plate), lipid droplet and electron-dense, membrane-bound body differs between 7 I-I-E and $H$. hedinii. In the former, the lipid droplet is located between the electron dense body and the tubular elements while in the latter is is found proximal to the dense body. Travland \& Whisler (1971) have speculated that the rumposomal apparatus may, in some manner, function like the flagellar mitochondrion found in the Blastocladiales.

On the basis of the resemblance of the 'fibrous body' of Nowakowskiella profusa to microvillar receptors of invertebrates, Chambers et al. (1967) suggested that the fibrous body complex may be a photoreceptive organelle, the lipid droplet functioning as a lens and the fibrous body as a photoreceptor, although this implies that the light would have to pass through the spore body. If one assumes that the tubular elements, lipid droplet, together with the electron-dense sac constituted a photoreceptor complex in the isolate $7 \mathrm{I}-\mathrm{I}-\mathrm{E}$, an alternative suggestion can be made. (The electron-dense sac is apparent in Plate 4, Fig. 5 of Chambers et al. (1967) but is not mentioned.) Rather than the tubular elements functioning as the actual photoreceptor as was postulated by Chambers et al. (1967), the tubular elements are here suggested to function as a system through which light is channelled. The light, then, perhaps with the aid of the lipid droplet acting as a lens, is focused on to a focal plane or point. This focal plane or point may lie within the electron-dense sac which is here postulated to contain the photosensitive molecules. Alternately, the tubular elements may act as 'blinders' which may permit light coming from only a preferred direction, possibly at some point along a line passing through the apex of the tubules, to impinge on a photosensitive area and lead to a phototactic response. In both these pathways, the phototactic orientation is based on an asymmetry of the photoreceptor which results in a preferred direction in which light can best be absorbed (Haupt, I966). Finally, the membrane-bounded sac and perhaps the lipid droplet can function as a 'shade' preventing stimulation of the photoreceptor from light passing through the interior of the motile cell.

Ultrastructurally, the zoospores of isolate $7 \mathrm{I}-\mathrm{I}-\mathrm{E}$ are interesting because of the unique arrangement and combination of organelles rather than for any single structural feature. The near parallel position of the kinetosome and the vestigial kinetosome is similar to that described for Olpidium brassicae (Temmink \& Campbell, 1969), the tubular elements of the 
presumed photoreceptor complex are probably similar to those found in Nowakowskiella profusa (Chambers et al. 1967) and Chytridium sp. (Schnepf et al. 1971). The position of the mitochondria around the ribosomal aggregate is similar to that of $N$. profusa (Chambers et al. I967) although the 'nuclear cap' possibly differs. The ultrastructure of isolate 7I-I-E differs from both Phlyctochytrium dichotomum (Umphlett \& Olson, 1967) and Rhizophydium sphaerotheca (Fuller, 1966) in the distribution of the ribosomes, position of the kinetosome with relation to the nucleus, disposition of the microtubular elements, position of mitochondria and the presence of the presumed photoreceptor complex.

I acknowledge the technical assistance of Mrs Kathleen Schornstein. This paper is Contribution no. 459, Virginia Institute of Marine Science, Gloucester Point, Virginia 23062, U.S.A.

\section{REFERENCES}

CARLILE, M. J. (1970). The photoresponses of fungi. In Photobiology of Microorganisms, pp. 309-344. Edited by P. Halldal. London: Wiley Interscience.

Chambers, T. C., Markus, K. \& WirloughBY, L. G. (1967). The fine structure of the mature zoosporangium of Nowakowskiella profusa. Journal of General Microbiology 46, I35-I4I.

FuLLER, M. S. (1966). Structure of the uniflagellate zoospores of aquatic Phycomycetes. In The Fungus Spore. pp. 67-84. Edited by M. F. Madelin. London: Butterworths.

FulLER, M. S. \& OLSON, L. (I97I). The zoospore of Allomyces. Journal of General Microbiology 66, I7I-I 83.

Fuller, M. S. \& ReICHLE, R. E. (1968). The fine structure of Monoblepharella sp. zoospores. Canadian Journal of Botany 46, 279-283.

HAupt, W. (I966). Phototaxis in plants. International Review of Cytology 19, 267-299.

KAY, D. H. (I965). Techniques for electron microscopy. Philadelphia, Pennsylvania: Davis Co.

KAZAMA, F. (1972). Development and morphology of a chytrid isolated from Bryopsis plumosa. Canadian Journal of Botany 50, 499-505.

$\mathrm{KocH}$, W. J. (1956). Studies of the motile cells of chytrids. I. Electron microscope observations of the flagellum, blepharoplast, and rhizoplast. American Journal of Botany 43, 8I I-819.

OLSON, L. W. \& FULLER, M. S. (1968). Ultrastructural evidence for the biflagellate origin of the uniflagellate fungal zoospore. Archiv für Mikrobiologie 62, 237-250.

PAGE, R. M. (1965). The physical environment for fungal growth. 3. Light. In The Fungi, pp. 559-574. Edited by G. C. Ainsworth \& A. S. Sussman. New York: Academic Press.

Perkins, F. O. \& AMON, J. P. (1969). Zoosporulation in Labyrinthula sp., an electron microscope study. Journal of Protozoology 16, 235-237.

Schnepf, E., DeichgräBer, G., Hegewald, E. \& Soeder, C. J. (I97I). Elektronenmikroskopische Beobachtungen an Parasiten aus Scenedesmus-Massenkulturen. 3. Chytridium sp. Archiv für Mikrobiologie 75, 230-245.

Sparrow, F. K. (1960). Aquatic Phycomycetes, 2nd edn. Ann Arbor: University of Michigan Press.

Temmink, J. H. M. \& CAMPBell, R. N. (I969). The ultrastructure of Olpidium brassicae. II. Zoospores, Canadian Journal of Botany 47, 227-23I.

Travland, L. B. \& Whisler, H. C. (I97I). Ultrastructure of Harpochytrium hedinii. Mycologia 63, 767-789.

UMPHLETT, C. J. \& OLSON, L. W. (1967). Cytological and morphological studies of a new species of Phlyctochytrium. Mycologia 59, 1085-1096. 